\title{
LETTER
}

\section{Kidney function decline after a non-dialysis- requiring acute kidney injury is associated with higher long-term mortality in critically ill survivors}

\author{
José António Lopes* and Sofia Jorge \\ See related research by Lai et al., http://ccforum.com/content/16/4/R123
}

In a recent issue of Critical Care, we read with interest the article by Lai and colleagues [1] in which they retrospectively analyzed the association between kidney function decline after a non-dialysis-requiring acute kidney injury (AKI) and long-term mortality (median follow-up of 700 days) in 634 intensive care unit (ICU) survivors. The authors found that every $1 \mathrm{~mL} /$ minute per $1.73 \mathrm{~m}^{2}$ decrease from baseline-estimated glomerular filtration rate of individuals who progressed to stage 3,4 , and 5 chronic kidney disease significantly increased the risks of mortality by $0.7 \%, 2.3 \%$, and $4.1 \%$, respectively. This observation is novel and suggests that a gradual decline in long-term renal function in non-dialysisrequiring AKI survivors is associated with decreased survival. Curiously, the authors have not evaluated the impact of sepsis on renal function and mortality. Sepsis is the most common cause of AKI in the ICU, and patients with septic AKI are clinically distinct from those with non-septic AKI [2-4]. First, septic AKI is associated with a greater burden of illness, concomitant non-renal organ dysfunction, and need for mechanical ventilation and vasoactive therapy. Second, patients with septic AKI are less likely to have impaired premorbid kidney disease. Third, patients with septic AKI have longer hospital length of stay and increased hospital mortality. Lastly, patients with septic AKI are more likely to recover kidney function by hospital discharge. Therefore, the discrimination of septic and non-septic AKI may have clinical relevance for clinicians, and sepsis should be taken into consideration in analyzing not only short-term outcomes but also long-term renal function and longterm mortality in critically ill survivors of AKI.

\section{Authors' response}

Chun-Fu Lai, Vin-Cent Wu, Wen-Je Ko and Kwan-Dun Wu

We thank Lopes and Jorge for their interest in our article [1]. We agree that sepsis should be taken into consideration in evaluating AKI outcomes. The presence of sepsis and the etiology of AKI have been identified as important factors affecting prognosis after an AKI [5].

Our prospectively collected NSARF (National Taiwan University Study Group on Acute Renal Failure) database, operating since 2002, did not contain the variables of the presence of sepsis and etiology of AKI at that time. Therefore, we could not analyze the influence of sepsis. We acknowledged this as a limitation and discussed it in

*Correspondence: jalopes93@hotmail.com

Department of Nephrology and Renal Transplantation, Hospital de Santa Maria, Centro Hospitalar de Lisboa Norte, EPE, Av. Prof. Egas Moniz, 1649-035 Lisboa, Portugal the article. We included many factors in the final analysis model, including maximum RIFLE (risk, injury, failure, loss, and end-stage kidney criteria) stage, mean arterial pressure, serum lactate levels, inotropic equivalent, and APACHE II (acute physiology and chronic health evaluation II) and SOFA (sequential organ failure assessment) scores, and these could partially account for the impact of sepsis on AKI outcomes. These clinical factors had been shown to be associated with septic AKI in previous studies $[3,4]$.

\section{Abbreviations}

AKI, acute kidney injury; ICU, intensive care unit.

\section{Competing interests}

The authors declare that they have no competing interests.

\section{Authors' contributions}

JAL and SJ drafted the letter, revised it critically for important intellectual content, and read and approved the final manuscript. 
Published: 29 November 2012

\section{References}

1. Lai CF, Wu VC, Huang TM, Yeh YC, Wang KC, Han YY, Lin YF, Jhuang YJ, Chao CT, Shiao CC, Tsai PR, Hu FC, Chou NK, Ko WJ, Wu KD; the National Taiwan University Hospital Study Group on Acute Renal Failure (NSARF): Kidney function decline after a non-dialysis-requiring acute kidney injury is associated with higher long-term mortality in critically ill survivors. Crit Care 2012, 16:R123.

2. Uchino S, Kellum JA, Bellomo R, Doig GS, Morimatsu H, Morgera S, Schetz M, Tan I, Bouman C, Macedo E, Gibney N, Tolwani A, Ronco C: Acute renal failure in critically ill patients: A multinational, multicenter study. JAMA 2005, 294:813-818.

3. Bagshaw SM, Uchino S, Bellomo R, Morimatsu H, Morgera S, Schetz M, Tan I, Bouman C, Macedo E, Gibney N, Tolwani A, Oudemans-van Straaten HM, Ronco C, Kellum JA, Beginning and Ending Supportive Therapy for the
Kidney (BEST Kidney) Investigators: Septic acute kidney injury in critically ill patients: clinical characteristics and outcomes. Clin J Am Soc Nephrol 2007, 2:431-439.

4. Lopes JA, Jorge S, Resina C, Santos C, Pereira A, Neves J, Antunes F, Prata MM: Acute kidney injury in patients with sepsis: a contemporary analysis. Int J Infect Dis 2009, 13:176-181.

5. Bagshaw SM, George C, Bellomo R: Early acute kidney injury and sepsis: a multicentre evaluation. Crit Care 2008, 12:R47.

\section{doi:10.1186/cc11860}

Cite this article as: Lopes JA, Jorge S: Kidney function decline after a nondialysis-requiring acute kidney injury is associated with higher long-term mortality in critically ill survivors. Critical Care 2012, 16:467. 